\title{
Panorama da interpretação em contextos médicos no Brasil: perspectivas
}

\section{Healthcare interpreting in Brazil: an overview}

Mylene Queiroz*

Resumo: Dentre os contextos comunitários em que há necessidade de mediação por meio de interpretação, o da saúde demanda cautela, dado à natureza complexa da atividade médica, que, consequentemente, impõe diferentes desafios aos intérpretes. No Brasil, as barreiras linguísticas enfrentadas por pacientes que não falam a língua portuguesa são tratadas de forma improvisada por intérpretes voluntários sem nenhum treinamento específico. Este artigo discorre sobre as atuais demandas por intérpretes em contextos médicos no Brasil e a necessidade de análises e ações com vistas à formação de um campo profissional que garanta o acesso a serviços de saúde no país por minorias linguísticas. Nesse sentido, este estudo aponta para a necessidade de debater a criação de políticas públicas que não somente reconheçam a demanda, mas que criem ferramentas de acesso linguístico. Aos profissionais e instituições voltados aos estudos da interpretação no contexto brasileiro, cabe colocar em pauta o debate sobre as pesquisas na área da Interpretação Comunitária, a fim de atualizar abordagens teóricometodológicas que atendam demandas de treinamento para intérpretes atuantes em contextos comunitários, entre eles, os da saúde.

Palavras-chave: Interpretação Comunitária; interpretação da área da saúde; currículo.

Abstract: Among the community settings where there is the need for interpreting services, healthcare contexts requires special attention, given the complex nature of the medical activity, which consequently imposes different challenges to interpreters. In Brazil, language barriers faced by patients who do not speak Portuguese are handled by

\footnotetext{
* Mestre em Estudos da Tradução Professora de Interpretação na área da Saúde no Mestrado em Interpretação de Conferência da Glendon College, Canadá myleneq@gmail.com
}

TradTerm, São Paulo, v. 23, Setembro/ 2014, p. 193-223

www. usp. br/ tradterm

http:// www. revistas. usp. br/tradterm/ index 
QueIROz, M - Panorama da interpretação em contextos médicos no Brasil: Perspectivas

volunteer interpreters without any specific training. This article gives an overview of the current demands for interpreters in medical settings in the country and the need for analysis and actions aimed at developing the professional field to ensure access to health services in the country by linguistic minorities with the help of qualified interpreters. It approaches the necessity of public policies that recognize the demand and the elaboration of linguistic access tools, and the urgent need to include the topic among the Interpreting Studies agenda in the Brazilian context, which should comprehend community interpreting, including healthcare settings.

Keywords: community interpreting; healthcare interpreting; curriculum

\section{Introdução}

Em sentido amplo, o objetivo da medicina é a manutenção e restauração da saúde. 0 acesso igualitário à saúde e cuidados médicos é um direito fundamental do ser humano, pautado no artigo XXV da Declaração Universal dos Direitos Humanos. 0 exercício da medicina e a eficácia de seu objetivo dependem sobremaneira da relação médico-paciente. Por sua vez, a qualidade da comunicação entre médico e paciente tem sido apontada em diversos estudos como uma das condições primordiais que repercutem na interação clínica satisfatória e sustenta os objetivos da prática médica (ONG et al. 1995; GoMES et al. 2012; STEWART 2005).

Foi partindo desses dois pressupostos - acesso integral e igualitário à saúde e qualidade de comunicação na relação entre agentes da saúde e pacientes - que se formaram algumas das perguntas norteadoras deste trabalho. Os pacientes que não se comunicam em português, língua oficial do Brasil, estão sendo preteridos no seu direito de acesso integral e igualitário à saúde, dado à barreira linguística? Quem são esses pacientes?

No contexto de um mundo internacionalizado, a demanda se origina dos 
QueIROz, M - Panorama da interpretação em contextos médicos no Brasil: Perspectivas

inúmeros estrangeiros que imigram para o Brasil. Os residentes de zonas fronteiriças e os turistas internacionais dependem cada vez mais de serviços educação, assistência jurídica e social, saúde, etc. -, fora dos contornos sociais, culturais e linguísticos com os quais estão familiarizados. Além disso, também dependem desses serviços os cidadãos brasileiros que não falam a língua portuguesa (comunidade surda e povos indígenas, por exemplo). Entre os serviços básicos de que necessitam, os de saúde chamam a atenção devido ao caráter complexo da prática médica, o que fica aqui maximizado pela barreira linguística.

Em cenários internacionais, como é o caso dos Estados Unidos, o problema do acesso igualitário à saúde para pacientes com limites linguísticos tem sido solucionado com ações legais e dispositivos práticos que se iniciaram nos anos 1980 e impulsionaram a inauguração de um campo profissional de atuação para intérpretes na área da saúde.

No Brasil, com raras exceções, há pouco debate acerca de questões de barreiras linguísticas em cenários médicos, deflagrando a necessidade de reflexão sobre direitos sociais nestes e em outros espaços interlinguísticos. Sabese que serviços de interpretação não são oferecidos formalmente por hospitais e clínicas no país. Assim, sem a oferta de serviços de interpretação, seguimos em busca de respostas para outras perguntas norteadoras: em contextos hospitalares, quem faz e como é feita a interpretação em ocorrências de encontros médicos com pacientes que não falam português?; em que medida os cursos formadores de intérpretes do país abordam o tema e o incluem em disciplinas de cunho prático e teórico?; e quais seriam os requisitos para formar intérpretes qualificados para atuar em contextos da saúde e alavancar um campo profissional institucionalizado e reconhecido no país?

Um dos objetivos deste trabalho foi responder, dentro do possível, a estas perguntas norteadoras. Devido à falta de dados sistematizados sobre o tema no 
Brasil e de pesquisas na área, o estado da prática da atividade no país foi analisado com base nos dados divulgados por instituições de saúde nas mídias nacional e estadunidense e por relatos concedidos por representantes de algumas instituições médicas (QUEIROz 2011).

\section{Interpretação comunitária}

A prática interpretativa que ocorre em contextos da saúde é compreendida no campo dos Estudos da Tradução e Interpretação como Interpretação Comunitária, definição utilizada para distinguir esta prática da interpretação de conferência. São também considerados contextos comunitários de interpretação aqueles de caráter educacional, jurídico e de Assistência Social. Outros termos são utilizados para definir o tipo de interpretação que ocorre no nível intrassocial ${ }^{1}$, entre eles, a social, a cultural, a de contato, a de serviço público (QuelROZ 2011). Essas diferentes terminologias revelam, em geral, como cada país concebe a atividade (URPI 2009, BAVLAY et al. 2007). No contexto brasileiro, o termo ainda precisa ser definido.

Os estudos sobre a temática tendem a convergir sobre análises das características da Interpretação Comunitária, e em que medida esses contextos se diferem dos contextos de conferência. As diferenças fundamentais dizem respeito ao contexto, ao modo de interpretação, à situação social dos participantes envolvidos no diálogo, ao propósito do encontro e aos modos de interpretação (ROBERTS 2002, NISKA 2005, PöCHHACKER 2010).

A atuação de intérpretes em contextos comunitários é uma prática antiga, utilizada para mediar os mais diferentes tipos de negociações humanas (ROBERTS

\footnotetext{
1 PÖCHHACKER 2004.
} 
QueIROz, M - Panorama da interpretação em contextos médicos no Brasil: Perspectivas

2008, PöCHHACKer 2004 e 2010, PöChHACKer e SHLesinger 2007). Na sociedade contemporânea, a necessidade de suprir barreiras na comunicação entre indivíduos de línguas e culturas distintas foi alavancada, especialmente, pelo processo de internacionalização que marcou o século XX. Negociações interlinguísticas e interculturais foram intensificadas não somente nas esferas político-diplomáticas, mas no dia a dia de pessoas comuns que passaram a fazer uso de serviços em um mundo internacionalizado. Nesse contexto de cruzamento de línguas e culturas, o aprovisionamento de serviços de interpretação qualificada pode ser entendido como meio de garantir o acesso de indivíduos não fluentes na língua oficial de um determinado país à comunicação, a fim de se beneficiarem dos serviços de que necessitam.

Os contextos comunitários passaram a ganhar espaço nos Estudos da Interpretação principalmente a partir dos anos 1980, quando houve um deslocamento do foco das análises realizadas pelos Estudos da Interpretação, especialmente em relação ao contexto, ao conteúdo interpretado, ao propósito da interação e às demais partes envolvidas na interação, além do intérprete. Até então, os estudos estavam notadamente interessados no processo cognitivo dos intérpretes - em especial os de conferência. As pesquisas sobre as interações dialógicas mediadas por intérpretes foram estimuladas pelas novas necessidades sociais, criadas devido à ampliação do fluxo de imigrantes em países em desenvolvimento e devido ao aumento do reconhecimento dos direitos de povos falantes de línguas minoritárias, os quais encontravam dificuldade para acessar serviços públicos e barganhar direitos (PöCHHACKER 2004, WADENSJ Ö 1992).

Contudo, duas décadas mais tarde, ainda é questionável em que medida as pesquisas desenvolvidas no campo dos Estudos Translatológicos têm se submetido a revisões de suas questões-chave frente ao processo de globalização e aos fenômenos linguísticos que daí suscitam (LAMBERT 2009). Embora incluída nas recentes propostas de mapeamento do campo de pesquisa dos Estudos da 
Tradução (cf. Williams e CHESTERMAn 2002), a interpretação que acontece em esferas comunitárias não foi parte dos tópicos centrais de pesquisas em tradução e interpretação no Brasil por um longo período. A preocupação com riscos envolvidos no uso de interpretação ad hoc tem incitado, ainda que lentamente, 0 surgimento de um corpo de investigações focado em questões pedagógicas na formação de intérpretes (DE PEDRO RICOY 2010). 0 tema recentemente entrou para pauta (embora perifericamente) de importantes eventos acadêmicos da área e foi foco de algumas discussões em simpósios ocorridos no ano de 2013, promovidos pela Associação Brasileira de Pesquisadores em Tradução - Abrapt - e pelo Primeiro Simpósio Brasileiro de Interpretação - Simbi.

\section{Interpretação Comunitária (ou intrassocial) no Brasil}

Independentemente da falta de debates políticos que contemplem iniciativas político-institucionais para fomentação de práticas que visem à diminuição de impactos negativos causados por barreiras linguísticas e culturais, bem como de reflexões teóricas e metodológicas sobre o tema, a atividade de interpretação em bases comunitárias é uma demanda real e ocorre diariamente nos mais diferentes contextos intrassociais do Brasil.

No país, a atividade da interpretação em esferas intrassociais tem certa expressividade em contextos educacionais e jurídicos. Nos contextos educacionais, a demanda por intérpretes de língua de sinais brasileira aumentou sobremaneira após o ano de 2002, influenciada pela sanção da Lei Federal №. 10.436, e decreto 5626/2005, os quais possibilitam a cidadãos surdos usuários da Língua Brasileira de Sinais (Libras) o acesso a serviços públicos por meio de 
QueIROz, M - Panorama da interpretação em contextos médicos no Brasil: Perspectivas

trabalhos de tradução e interpretação (Lei n 10.436, 2002). Em contextos jurídicos, barreiras linguísticas são mediadas pela atividade realizada por tradutores públicos e intérpretes comerciais ou por intérpretes forenses cadastrados no poder judiciário. Tradutores públicos e intérpretes comerciais são profissionais regulamentados em âmbito nacional desde 1943 e atuam por meio de aprovação em concursos públicos oferecidos por juntas comerciais estaduais, instituições sem nenhuma tradição em formação e avaliação de tradutores e intérpretes profissionais e nenhuma afiliação objetiva e explícita a associações de profissionais tradutores e intérpretes do país. As vagas se limitam a um conjunto de línguas orais. Até o presente momento, não foram disponibilizadas vagas para intérpretes juramentados de Libras. Já os intérpretes forenses atuam mediante cadastro junto ao órgão representante do poder judiciário em diferentes estados no Brasil. Segundo uma comunicação oral intitulada "Manual de boas práticas do intérprete judicial", apresentada por Jaqueline Nordin durante o SIMBI, 2013, os intérpretes forenses atuam com mais recorrência nos tribunais do que os próprios tradutores públicos e intérpretes comerciais. De acordo com a autora, o motivo parece ser a baixíssima remuneração (por três horas de trabalho, menos do que 55 reais, que podem ser pagos em até dois anos). Intérpretes forenses são cadastrados pelo site da instituição de justiça e não precisam fazer nenhum tipo de avaliação. A autora produziu um trabalho em forma de manual, que está sendo usado em todas as varas do fórum federal da cidade de Guarulhos, em São Paulo.

Ainda que com menos expressividade, os âmbitos médico-hospitalares são contextos nos quais há necessidade literalmente vital de serviços de interpretação. Muitas instituições no Brasil vêm recebendo um número significativo de pacientes não falantes da língua portuguesa. Esses pacientes têm se submetido a tratamentos no país de maneira improvisada, do ponto de vista do acesso à comunicação, desprezando-se a complexidade de interações médicas 
QueIROz, M - Panorama da interpretação em contextos médicos no Brasil: Perspectivas

e os riscos que a troca de informação ineficaz nesses eventos pode trazer à saúde do paciente. Como sugere uma coletânea de trabalhos editados por WHALEY (2000), existe muita complexidade no encontro entre profissionais da saúde e pacientes, em comunicar e entender uma explicação sobre doença - e essa complexidade se intensifica nos casos em que há barreiras linguísticas. Experiências internacionais têm evidenciado que 0 uso de intérpretes qualificados pode minimizar os riscos acerca de encontros médicos multilíngues e garantir a eficácia do atendimento.

\section{Intérpretes da área da saúde}

Os intérpretes da área da saúde mediam a interação entre pacientes e provedores de serviços da saúde (médicos, enfermeiros, técnicos, psicólogos, administradores, etc.) quando estes não falam o mesmo idioma. Os conteúdos dos diálogos dessas interações têm algum nível de carga emocional, que irá variar conforme a natureza do problema. Do paciente é de se esperar enunciados mais subjetivos e uso de terminologias menos formais e técnicas, para descrever as razões que o trazem ali. Dos provedores, espera-se um enunciado mais objetivo, formal e essencialmente técnico para fazer diagnósticos e traçar tratamentos. Essas interações se dão tanto em departamentos clínicos (consultórios, salas de exames diversos, salas de cirurgias, etc.) como em ambientes administrativos (triagem, cadastro, serviço social, departamento financeiro, etc. ).

Dessa forma, a qualidade da interpretação em contextos da saúde depende de intérpretes que estejam conscientes das características de tais contextos e possuam competências técnicas (proficiência linguística, conhecimento de terminologia médica, gerenciamento do fluxo de comunicação - 
QueIROz, M - Panorama da interpretação em contextos médicos no Brasil: Perspectivas

que pode se tornar verdadeiramente complexo em contextos de saúde mental habilidades de posicionamento e arranjo do espaço físico, utilização de ferramentas tecnológicas para atuar em seções remotas via telefone ou web câmeras, etc.), de conhecimento social, político e administrativo (conhecimento dos diversos departamentos e especialidades médicas, dos fatores administrativos e legais do contexto que determinam a conduta médica do país onde atua) e de conhecimento cultural (concepções de medicina, saúde, doença, tratamento, com as quais cada participante da interação está familiarizado). Intérpretes atuantes em contextos da saúde devem estar preparados também para enfrentar atmosferas emocionais e de risco das mais diversas naturezas, precisando assim de habilidades de autoavaliação e autocuidado (QUEIROZ 2011).

O conjunto dessas competências são elementos de uma interpretação eficaz que preza não somente a precisão das informações, de qualquer natureza ${ }^{2}$, mas o cuidado no trato com questões que trazem à tona dilemas éticos e de conduta entre os envolvidos. Aos pacientes, a oferta de serviços profissionais de interpretação deve Ihes conferir acesso irrestrito a informações sobre sua saúde, sobre as instituições que os tratam, sobre os protocolos de atendimento das instituições e sobre o corpo médico responsável por seus tratamentos. Assim, mantém-se o paciente consciente e ponderado em suas escolhas, favorecendo sua autonomia na interação para compartilhar suas preocupações e dúvidas e para a criação do vínculo afetivo necessário entre pacientes e provedores de saúde (BOWEn 2000, Ku E FLORES 2006, ERTL E PölLABAUER 2010, SCHILLINGER e Chen 2004, J OINT COMmission 2010, 2011). Aos provedores de serviços de saúde, a presença de intérpretes profissionais permite que haja acesso às reclamações em relação às preocupações do paciente de maneira

\footnotetext{
2 Informações de qualquer natureza (verbais e não verbais) são fundamentais na medida em que funcionam como pistas para o provedor de saúde, pois trazem detalhes que indicam os estados físico e mental do paciente e, portanto, são informações imprescindíveis para a realização de um diagnóstico apurado e um programa de tratamento adequado.
} 
precisa, facilitando o diagnóstico e o projeto de tratamento.

A detenção desses saberes é, portanto, fator que diferencia a interpretação profissional daquela feita de maneira diletante, em geral por funcionários bilíngues de um hospital, por amigos e familiares do paciente (incluindo crianças) e por intérpretes voluntários sem treinamento em interpretação da área da saúde. Vários estudos têm alertado para os potenciais problemas gerados pelo uso de intérpretes sem treinamento (ANGELELLI 2004 (a) (b), Bischoff 2003, Flores 2003, ERTl e Pöllabauer 2010, PöchHacker e Kadric 1999). Experiências relatadas assinalam como a falta de algumas habilidades pode se apresentar como verdadeiro desafio para intérpretes, pois frequentemente os coloca no limite de seu papel.

O papel do intérprete na área da saúde, ou seja, sua função no encontro é um tema central e controverso nas pesquisas desenvolvidas na área. As posições se dividem repetidamente acerca do grau que deve assumir o profissional em uma escala que varia entre o intérprete como um decodificador linguístico (que utilize o mínimo de interferência de carga subjetiva) e o intérprete como indivíduo mediador em um encontro entre indivíduos que, por sua vez, também assumem diferentes papéis sociais. Nessa problemática, são relevantes as questões de ordem contextual relacionadas a conjunturas culturais, administrativas e legislativas, as duas últimas, com pouco ou nenhum espaço para negociações. Em países como os Estados Unidos, devido a um conjunto de leis que garante a confidencialidade da informação médica do paciente e os limites dos profissionais da área da saúde, o papel do intérprete tende a ser muito mais claro e menos flexível no que diz respeito à sua relação com o paciente.

0 tópico papel do intérprete em contextos da saúde deve ser tratado com prudência e à luz de conceitos conhecidos, por gerar discussões acaloradas nos Estudos da Tradução e Interpretação: neutralidade e visibilidade (cf. METZGER 
QueIROz, M - Panorama da interpretação em contextos médicos no Brasil: Perspectivas

1999, Angelelil 2004 (a) (b), Kaugert e O’Neil 1990, Rudvin 2003, Andreson 2007, PöCHHACKER 2004, LEANZA 2008). A este trabalho não coube discutir o grau de neutralidade e visibilidade de intérpretes, mas assinalar que a interpretação ad hoc pode promover riscos potenciais para todas as partes envolvidas na interação, em especial ao paciente. Como nos lembra AvERY, (2001: 11, tradução nossa ${ }^{3}$ ) "O papel do intérprete da área da saúde envolve um conjunto de habilidades e expectativas complexas praticadas em um cenário social, cultural e politicamente complexo - tanto no nível interpessoal como no institucional".

\section{Demanda e situação da interpretação em contextos da saúde no Brasil: uma comparação com os Estados Unidos}

No Brasil, assim como em outros países, a demanda por intérpretes em esferas comunitárias se intensificou devido especialmente aos movimentos migratórios de trabalhadores e refugiados e a políticas de inclusão de grupos minoritários (NISKA 2005, BANCROFT 2005). No entanto, enquanto em alguns poucos países, como Estados Unidos e Austrália, a prática profissional da interpretação em contextos da saúde já é institucionalizada, em outros ${ }^{4}$, como Brasil e alguns países da América do Sul, a atividade ainda é compreendida como mera ação assistencial desencadeada por uma necessidade de comunicação.

3 "...the health care interpreter role involves a complex set of skills and expectations practiced within a setting that is socially, culturally and politically complex at both an interpersonal and institutional level".

4 Áustria, Alemanha, Noruega, Reino Unido, Irlanda, Austrália, Estados Unidos, Canadá e África do Sul são alguns exemplos (BISCHOFF e HUDELSON 2010). 
QueIROz, M - Panorama da interpretação em contextos médicos no Brasil: Perspectivas

Hospitais de grandes capitais brasileiras alegam um aumento exponencial de pacientes estrangeiros (QUEIROz 2011). Para atendê-los, alguns hospitais de ponta investiram na criação de algum tipo de "departamento internacional"; outros procuram serviços terceirizados em agências de acompanhantes conhecidas como Medical Concierge. De acordo com uma das agências, serviços de acompanhantes bilíngues custam em média 300 reais por hora. A prestadora de serviço também afirma que, embora seus colaboradores sejam fluentes nas línguas com que trabalham, não possuem nenhum tipo de treinamento específico para atuar em instituições da saúde. Pacientes estrangeiros que procuram hospitais de ponta no Brasil estão em geral vinculados a uma modalidade conhecida como "turismo médico". Nas últimas décadas, o Brasil se tornou um dos lugares mais procurados para tratamentos médicos no mundo, dado à qualidade de tratamento combinada com os baixos custos em relação ao mercado internacional.

Outra demanda decorre de estrangeiros de várias origens que procuram o Brasil em busca de asilo ou trabalho, os quais fazem uso de hospitais públicos e não podem pagar por serviços de acompanhantes. Em 2009, um estudo da ONU (Organização das Nações Unidas) apontou que o crescimento socioeconômico do Brasil estimularia a imigração para o país, e que o fluxo deveria aumentar a partir de 2010 (QuelRoz 2011). Bolivianos, peruanos, paraguaios, argentinos, coreanos e chineses fazem parte da recente onda imigratória no Brasil. Além disso, as áreas fronteiriças do Brasil com países limítrofes recebem diariamente um número expressivo de pacientes que cruzam a fronteira em busca de tratamento médico (GIovanella 2007). Esses indivíduos, quando necessitam de atendimento médico, contam com a sorte de que um amigo ou um funcionário do hospital tenha algum conhecimento da língua. Além disso, utilizam linguagem corporal e gestos para os auxiliarem no acesso aos cuidados de saúde. Alguns poucos hospitais estão investindo em aulas de idiomas para seus funcionários 
QueIROz, M - Panorama da interpretação em contextos médicos no Brasil: Perspectivas

como tentativa de amenizar o problema (QueIROz 2011).

Em Santa Catarina, funcionários do Hospital Universitário Professor Polydoro Ernani de São Thiago afirmaram que, quando não há ajuda de um amigo ou membro da família do paciente, chamam um colega que tenha algum conhecimento de línguas. Os resultados obtidos com a aplicação de um questionário apontam para uma total falta de conhecimento sobre os riscos envolvidos em encontros em que existam barreiras linguísticas e culturais. Respostas como "Rezo para dar certo", "Reconheço os sintomas apenas olhando para o paciente", "Faço gestos para atender ao paciente", não foram raras à pergunta "Como você faz o diagnóstico de um paciente com quem você não se comunica devido a uma barreira linguística?". Um representante oficial da instituição afirmou que não há nenhum tipo de treinamento ou procedimento diferenciado para atender aos pacientes não falantes de português, ou seja, no evento de um encontro multilinguístico, funcionários não possuem um protocolo oficial a ser seguido.

Outra importante demanda vem de brasileiros não falantes de português, a exemplo, parte dos mais de cinco milhões de pessoas surdas usuárias de línguas de sinais. Diferentemente das demandas citadas anteriormente, desprovidas de qualquer legislação que Ihes garanta o acesso linguístico, os cidadãos surdos do Brasil contam com a Lei Federal 10.436/ 2002 - e Decreto 5626/2005, os quais garantem serviços de interpretação inclusive em contextos da saúde. Pacientes surdos ainda dependem de intérpretes sem formação apropriada, mesmo que estes façam verdadeiros esforços para atuar com eficácia. Relatos de intérpretes assinalam questões como a falta de terminologia em Libras, que, na maioria dos casos, não dá conta da amplitude dos termos médicos envolvidos em uma interação entre pacientes e provedores de serviço da saúde; o desconhecimento sobre a anatomia e a fisiologia humana e sobre os procedimentos médicos; a inexperiência por parte dos servidores de saúde para atuar junto à presença de 
um intérprete; a dificuldade no ato de referenciação (uso de $1^{\text {a }}$ ou $3^{\mathrm{a}}$ pessoa); a técnica de troca e tomada de turno de fala; o posicionamento do intérprete durante os diferentes tipos de encontros médicos; entre outras (WENINGER e QUEIROz 2014). Um intérprete assinalou que existem muitos relatos de pacientes surdos afirmando terem sido vítimas de diagnósticos equivocados em interpretações feitas por membros da família (QuelROz 2011).

Outro grupo de brasileiros não falantes de português são os povos indígenas. Em entrevista a um jornal eletrônico de Roraima (Melo 2012), a coordenadora da Casa de Saúde do Índio (Casai), Rosiane Azevedo, fala sobre o trabalho de alguns poucos intérpretes que trabalham em hospitais da área e confirma que faltam intérpretes para atender à atual demanda em cidades como Boa Vista, no norte do país. Em 2005, o Ministério da Saúde, por meio da portaria 1068/GM, institui a criação do selo "Hospital Amigo do Índio". Hospitais credenciados devem oferecer, entre outras adaptações necessárias, a presença de um acompanhante intérprete. Há poucas informações disponíveis sobre a capacitação desses intérpretes contratados por alguns dos hospitais. Serão necessárias pesquisas futuras com foco na demanda e na prática da interpretação em hospitais que atendem aldeias indígenas.

Nos Estados Unidos, as demandas, ainda que demograficamente mais expressivas, são bastante similares às do Brasil, com tradição imigratória e de turismo internacional. Além disso, o país conta com um número significativo de pacientes surdos (Mitchell et al. 2006) que dependem de serviços de interpretação. Diferentemente do Brasil, é vasto o conjunto de leis e políticas públicas que garantem direitos linguísticos aos indivíduos com limite de proficiência em língua inglesa (QueIROz 2011).

Não raramente, hospitais contam com departamentos de intérpretes de vários idiomas, os quais são escolhidos com base em pesquisas sobre a demanda linguística da comunidade usuária do hospital. Hospitais que não trazem 
QUEIROZ, M - Panorama da interpretação em contextos médicos no Brasil: Perspectivas

intérpretes em seu quadro de funcionários efetivos ou que precisam atender a um paciente cujo idioma não é falado por intérpretes da instituição, precisam, por lei, terceirizar intérpretes - seja para interpretação presencial ou remota, via telefone ou vídeo conferência (Kelly 2008).

Essa realidade contribuiu para a estruturação de um campo profissional para intérpretes da área da saúde. Inicialmente, as resoluções foram pragmáticas. Os intérpretes eram, em geral, imigrantes bilíngues, indivíduos que residiam na mesma comunidade de seus clientes e participavam dos mesmos eventos sociais, sem nenhum treinamento específico. A proximidade com os clientes deixava vulneráveis as informações confidenciais sobre a saúde do paciente em sua comunidade. Devido a dilemas éticos como esse e à busca por reconhecimento profissional, nos anos 1980, foi inaugurada a primeira associação de profissionais da área, atualmente conhecida como Associação Internacional de Intérpretes Médicos - IMIA. Outras associações, tais como a California Healthcare Interpreters Association e a National Council on Interpreting in Health Care surgiram na mesma década. O objetivo comum de tais associações foi o de estabelecer normas profissionais de conduta e padrões de ética com vistas à segurança de pacientes, intérpretes e provedores de serviços da saúde, constituindo, assim, um campo profissional reconhecido e institucionalizado no país. Foi então instituído pela IMIA, em 1987, o primeiro código deontológico da profissão. A partir desse documento, foram formulados, em 1995, também pela IMIA, os códigos de conduta e ética.

Foi esse primeiro grupo de intérpretes ad hoc envolvidos com as associações, que estruturou os primeiros cursos de interpretação na área da saúde nos Estados Unidos, ainda que sem muitas reflexões teóricas e diretrizes metodológicas claras. Por essa razão, os programas de treinamento foram, e ainda são, muito variados em relação à carga horária e aos seus objetivos de aprendizagem. Parte disso se deu também em razão de não haver um 
QueIROz, M - Panorama da interpretação em contextos médicos no Brasil: Perspectivas

conhecimento sistematizado sobre quais eram, em realidade, as dificuldades enfrentadas na rotina de intérpretes em contextos da saúde e, por conseguinte, as habilidades e competências necessárias para enfrentar tais dificuldades.

Recentemente, por meio de pesquisas feitas em nível nacional, direcionadas a intérpretes e provedores da saúde (PSI Service LLC 2010, CCHI 2010), com o objetivo de estabelecer e validar uma certificação nacional, foi identificada uma série de incumbências enfrentadas nas rotinas desses profissionais e a frequência com que eles as enfrentavam. Por meio dos resultados dessa pesquisa estabeleceu-se, então, o primeiro teste nacional para certificação de intérpretes e a criação do National Board of Certification for Medical Interpreters. O conhecimento linguístico, temático e de diversas técnicas de interpretação são habilidades avaliadas no teste nacional. Atualmente, existem duas equipes de profissionais envolvidas com certificação (KelLy 2010). É esperado que a implementação da certificação nacional impulsione uma padronização mínima dos programas de treinamento no país especialmente com relação aos seus objetivos de aprendizagem.

Em contraste aos esforços institucionais profissionalizantes, é ainda branda a reflexão teórica sobre o tema nas universidades estadunidenses. Grande parte dos programas de pós-graduação em Estudos Translatológicos não oferece linhas de pesquisas em interpretação comunitária em âmbitos médico-hospitalares. Há também uma lacuna em relação ao treinamento e à certificação em interpretação na área da saúde em Língua Americana de Sinais. Curiosamente, os intérpretes de língua de sinais parecem estar deslocados do movimento de profissionalização da interpretação em cenários médicos. MOORE E SWABEY (2007) apontaram para a escassez de estudos na interface entre interpretação médica e interpretação de língua de sinais. 
QueIROz, M - Panorama da interpretação em contextos médicos no Brasil: Perspectivas

\section{Formação para intérpretes da área da saúde no Brasil: estado atual e recomendações}

Apesar de contar com leis e políticas que estabelecem direitos de acesso ao uso de serviços sociais para imigrantes e cidadãos surdos, no Brasil, ainda são escassos os meios que garantam a comunicação ativa desses indivíduos - como, por exemplo, a disponibilidade de intérpretes profissionais e qualificados para atuarem em contextos intrassociais.

Diante dessa problemática, o envolvimento de associações de profissionais da área, o desenvolvimento de pesquisas sobre o tópico e a criação de currículos voltados à formação de intérpretes são vitais para a estruturação de um campo profissional legitimado. Nesse sentindo, nos interessa entender em que medida as instituições acadêmicas e instituições de profissionais tradutores e intérpretes no país estão envolvidas com a questão e como a estão encaminhando.

Uma análise da estrutura curricular dos cursos em níveis de graduação e pós-graduação em estudos translatológicos no país revela que a oferta de disciplinas que se propõem a refletir sobre aspectos teóricos e práticos da tradução é essencialmente mais expressiva do que aquelas voltadas para os aspectos da interpretação. As disciplinas que abordam os Estudos e a prática da Interpretação enfatizam sobremaneira a interpretação simultânea para conferências, especialmente no par de línguas português-inglês ${ }^{5}$. Nenhuma das grades curriculares analisadas menciona qualquer abordagem teórica ou prática em Interpretação Comunitária.

Recentemente, 0 bacharelado em Letras-Libras oferecido pela Universidade Federal de Santa Catarina (UFSC), que tem como objetivo formar tradutores e intérpretes de Libras reformulou a grade curricular contemplando

${ }_{5}^{5}$ Para uma lista de cursos em tradução e interpretação no Brasil, consultar QUEIROZ 2011. 
QueIROz, M - Panorama da interpretação em contextos médicos no Brasil: Perspectivas

tópicos acerca de contextos intrassociais de interpretação. Contextos da saúde e jurídico serão abordados em disciplinas como Estudos da Interpretação ou, ainda, em práticas de treinamento em disciplinas como Laboratórios em Interpretação6 .

Em relação às entidades representativas de profissionais tradutores e intérpretes (Associação Brasileira de Tradutores e Intérpretes - Abrates -, Sindicato Nacional dos Tradutores - Sintra -, Associação Profissional de Intérpretes de Conferência - Apic -, Federação Brasileira das Associações dos Profissionais Tradutores e Intérpretes e Guiainterpretes de Língua de Sinais Febrapils), também não foram observadas atividades voltadas à formação ou à certificação para intérpretes que desejem atuar em contextos médicos. Tão pouco há um código de conduta e ética para profissionais da área que dê conta dos dilemas encontrados na rotina dessa atividade. 0 único código formulado no Brasil para profissionais da área de Tradução e Interpretação em línguas orais é o código do Sintra, com especificações voltadas apenas para contextos jurídicos. Além disso, há espaço no documento para ambiguidades e arbitrariedades. 0 código de ética para tradutores e intérpretes de língua de sinais tem especificidades mais claras, mas, ainda assim, parece necessário adequá-lo para ser aplicado em contextos específicos. A divisão da IMIA no Brasil está em fase embrionária e conta com não mais do que vinte associados. O código deontológico e o código de ética e conduta para intérpretes da área da saúde foram traduzidos para a língua portuguesa, mas ainda não foram testados e submetidos a uma ampla discussão para adaptá-los ao contexto nacional (IMIA 2006, 2010).

${ }^{6}$ Disponível em: http:// cagr.sistemas.ufsc.br/ . 


\section{Perspectivas curriculares}

No cenário internacional, além dos inúmeros cursos oferecidos nos Estados Unidos, há oferta de cursos no Canadá, na Austrália e em alguns poucos países da Europa. Em países asiáticos, apesar da crescente demanda por intérpretes da área da saúde, também há carências de oferta de cursos (cf. QueIROz 2011). Fora do contexto estadunidense, os cursos em geral são em Interpretação Comunitária, os quais possuem em suas grades curriculares disciplinas em interpretação para a área da saúde. Esse é o caso de cursos oferecidos no Reino Unido, na Dinamarca, na Suécia e na Austrália.

Algumas instituições em países como os Estados Unidos e o Canadá, atentas ao problema, fazem esforços na criação de cursos que tenham como proposta a formação integral de intérpretes da área da saúde. No entanto, salvo algumas exceções ${ }^{7}$, grande parte dos cursos ainda parece não contemplar de maneira integral o conjunto de habilidades e competências necessárias para a eficácia da interpretação em contextos da área da saúde, como revelam as pesquisas de análise de função (CCHI 2010, PSI 2010). Técnicas de interpretação em seus vários modos, e o uso de tecnologias para interpretação remota e para banco de dados não estão incluídas na maioria dos programas.

Uma proposta curricular interessante para a formação de intérpretes da área da saúde nasceu de uma parceria entre universidades da Áustria, Finlândia, Alemanha e Eslovênia, em um projeto desenvolvido entre 2007 e 2009 intitulado Medint (cf. ERTL e Pöllabauer 2010). Um dos objetivos elementares desse currículo foi elaborar estratégias para conscientização dos usuários de intérpretes (médicos, pacientes) e responsáveis públicos sobre a importância do uso de intérpretes qualificados para mediarem encontros médicos

70 mestrado em interpretação de conferência da Glendon School of Translation no Canadá oferece, no primeiro ano, disciplinas em interpretação na área da saúde e jurídica.

TradTerm, São Paulo, v. 23, Setembro/ 2014, p. 193-223

www. usp. br/tradterm

http:// www. revistas. usp. br/ tradterm/index 
QueIROZ, M - Panorama da interpretação em contextos médicos no Brasil: Perspectivas

interlinguísticos e interculturais. Além disso, o currículo foi planejado com vistas à sua fácil adaptação para contextos além daqueles envolvidos na formação do projeto.

0 programa Medlnt juntamente com 0 perfil de alguns programas estadunidenses apresentam-se como sugestões interessantes para atender em curto prazo as demandas do cenário brasileiro, particularmente por serem focados apenas em interpretação para contextos médicos e adaptáveis a diferentes públicos.

Com a devida atenção às diferenças relevantes entre as configurações do contexto brasileiro, o projeto Medlnt pode ser também utilizado como base de diretrizes de propostas curriculares no país e em outros países da América Latina. Uma das diferenças em relação ao contexto europeu é a sensibilidade para as variações multilíngues e multiculturais, tradicionais neste continente. No Brasil, demograficamente, há muito menos variedades culturais e linguísticas, e as especificidades culturais são mais sutis, especialmente em relação às diferentes culturas de origem hispânica. Embora sejam variadas, dificilmente se fazem distinções no Brasil em relação às peculiaridades culturais e linguísticas dos diferentes países vizinhos de língua espanhola. Outra diferença relevante é que 0 Projeto Medint foi criado para um contexto em que o sistema de saúde é amplamente público, com pouca expressão do setor privado. No caso do Brasil, o setor privado é a compensação para as carências do setor público, e deve também ser levado em conta na configuração do currículo.

o projeto Medint prevê que o sucesso da implementação de currículos para formação de intérpretes da área da saúde depende sobremaneira da sensibilização pública sobre acesso pleno de grupos linguísticos minoritários a tais serviços. Daí a necessidade do envolvimento, avant la lettre, das diversas instituições nacionais envolvidas com políticas linguísticas, imigratórias, de inclusão e saúde. 
QueIROz, M - Panorama da interpretação em contextos médicos no Brasil: Perspectivas

Embora o Brasil não conte com uma legislação complexa em relação a acessos línguo-culturais, as diligências das leis de anistia, de libras e as proposições pautadas pela Declaração dos Direitos Humanos podem ser utilizadas como elementos não só para a conscientização, mas para a exigência de serviços de interpretação qualificada. Ainda em relação à complexidade de políticas linguísticas, a falta de informação demográfica oficial sobre grupos linguísticos minoritários prejudica diretamente a criação de leis de acesso linguístico. Descortina-se aí a responsabilidade de organizações como as Pastorais de Migrantes, a Fundação Nacional do Índio (Funai), o Ministério da Saúde, o Ministério da Justiça, os consulados estrangeiros, entre outras, de coletar e sistematizar informações demográficas atualizadas, por meio de censos, relatando demograficamente as necessidades de acesso a serviços de saúde por minorias linguísticas no Brasil. As instituições que oferecem programas de formação para intérpretes e tradutores e ciências da saúde, bem como instituições representantes da profissão (Abrates, Sintra, Apic, Febrapils, IMIA/ Brasil), aparecem como parcerias potenciais para colaborar com esta etapa de sensibilização - por meio de pesquisas e debates sobre o tema. Além disso, as instituições de ensino que oferecem cursos de formação em tradução e interpretação, bem como cursos na área da saúde, são fundamentais para a sensibilização pública. Ainda que nem todos os cursos tenham perfil para abordar práticas e técnicas de interpretação, é importante a abordagem histórica e teórica do tema, com vistas à conscientização de futuros profissionais e à elaboração de possíveis soluções.

Em curto prazo, seria interessante que qualquer iniciativa de estruturação de cursos de formação de intérpretes da saúde beneficiasse os diferentes públicos que já estão em atividade funcionários bilíngues ad hoc de instituições de saúde e intérpretes com experiência em outras áreas. Um curso pensado para esses públicos poderia atender a necessidades sazonais e de urgência, a exemplo 
QUeIROZ, M - Panorama da interpretação em contextos médicos no Brasil: Perspectivas

dos eventos internacionais de esporte que acontecem no Brasil em 2014 e 2016, respectivamente, e que trazem ao país um número expressivo de turistas internacionais de diversas nacionalidades.

Em longo prazo, posta a complexidade da atividade, é importante que os currículos se desenvolvam e venham a beneficiar outros interessados, como alunos de cursos de línguas, de tradução e interpretação e de ciências da saúde, bem como imigrantes residentes nos país. O Projeto Medlnt relembra que a experiência educacional de imigrantes nem sempre tem reconhecimento no país anfitrião. Dessa forma, um nível de formação em interpretação para a área da saúde poderia beneficiar e valorizar a experiência linguística e cultural de imigrantes no Brasil.

A proficiência linguística precisa ser requisito primeiro para admissão de alunos em um curso de interpretação para contextos de saúde. No Brasil há diversas instituições que oferecem programas de avaliação de proficiência nos mais diversos idiomas (Quelroz 2011). 0 nível ideal de fluência na língua-alvo e na língua-fonte poderá ser identificado por meio de parcerias com peritos da área.

\section{Diretrizes curriculares}

A pesquisa tomou como base as competências e as várias subcompetências apontadas pelo Projeto MedInt, entendidas como basilares para a formação de intérpretes da área da saúde. Por competência, o projeto entende " ...a combinação de aptidões, comportamento, conhecimento e know-how necessários para o desempenho de uma dada tarefa sob determinadas condições ${ }^{8 \prime}$ (POKORN 2008).

\footnotetext{
8 "Competence" refers to the combination of aptitudes, knowledge, behavior and know-how necessary to carry out a given task under given conditions".
} 
QuEIROZ, M - Panorama da interpretação em contextos médicos no Brasil: Perspectivas

Os conhecimentos prático e teórico que dão base para o desenvolvimento de tais competências devem ser transpostos objetivamente para currículos em forma de conteúdo, os quais devem estar atentos à atual situação do contexto em que serão oferecidos, ou seja, o tipo de demanda, os recursos humanos, técnicos, sociais e financeiros. Ademais, os objetivos do curso, em relação à profundeza do conhecimento e às habilidades (elementares ou avançadas), irão variar de acordo com a carga horária do curso e o público alvo.

O quadro 1 detalha as competências sugeridas pelo projeto Medint, as quais devem ser desenvolvidas por alunos intérpretes no decorrer de um curso.

Quadro 1 - competências e habilidades sugeridas pelo projeto Medlnt

\begin{tabular}{l|l}
\hline Competência & Habilidades \\
\hline Prestação de serviço & $\begin{array}{l}\text { de acionar modalidades de interpretação (consecutiva, tradução à prima- } \\
\text { vista, tomada de notas, simultânea), conforme necessário; } \\
\text { de gerenciamento de disposição física e gerenciamento do diálogo (tomada de } \\
\text { turno); } \\
\text { de reconhecer e gerenciar dilemas éticos e limites do seu papel profissional; } \\
\text { de definir e negociar carga horária e orçamentos com seus clientes. }\end{array}$ \\
\hline Linguística & $\begin{array}{l}\text { de compreender e utilizar estruturas gramaticais, lexicais idiomáticas da L1 e } \\
\text { da L2. }\end{array}$ \\
\hline Intercultural & $\begin{array}{l}\text { de reconhecer diferentes concepções culturais sobre saúde, doença e } \\
\text { tratamento ou qualquer outro aspecto cultural que possa interferir no sucesso } \\
\text { da interação. }\end{array}$ \\
\hline $\begin{array}{l}\text { Tecnológica e de } \\
\text { coleta de informação }\end{array}$ & $\begin{array}{l}\text { de acionar ferramentas tecnológicas para interpretar remotamente } \\
\text { vídeo/ telefone); de pesquisar ativamente sobre termos e procedimentos } \\
\text { médicos; de sistematizar e administrar banco de dados para consulta de } \\
\text { termos. }\end{array}$ \\
\hline Temática & $\begin{array}{l}\text { de pesquisar ativamente sobre as atuais legislações que regem as atividades } \\
\text { médicas no país e sobre as novaços no campo de interpretação médica nos } \\
\text { cenários nacional e internacional. }\end{array}$ \\
\hline
\end{tabular}

TradTerm, São Paulo, v. 23, Setembro/2014, p. 193-223

www. usp. br/tradterm

http:// www. revistas. usp. br/tradterm/index 
QueIROz, M - Panorama da interpretação em contextos médicos no Brasil: Perspectivas

\section{Conclusão}

No Brasil, são pacientes com barreiras de acesso linguístico os cidadãos surdos usuários de Libras e os de etnias indígenas que não falam a língua portuguesa. Também fazem parte desse grupo, imigrantes de várias nacionalidades que estão vivendo no país, grupos que residem em áreas fronteiriças e turistas internacionais. A sistematização de dados demográficos sobre estes pacientes é inexistente e depende de ações de instituições dos poderes público e privado para categorizar dados e, assim, legitimar necessidades sociais de minorias linguísticas no país. Os pacientes, segundo resultados do presente estudo, quando necessitam de cuidados médicos, contam com interpretação ad hoc, sendo esta feita substancialmente por amigos, familiares ou voluntários, de forma improvisada.

No entanto, pesquisas no cenário internacional têm chamado atenção para os diversos riscos envolvidos no uso de intérpretes não profissionais na mediação de encontros entre pacientes e provedores de serviços da saúde. Entre os riscos estão o desconhecimento, o uso inadequado ou a omissão de termos médicos, vitais para o sucesso da interação, do diagnóstico, do tratamento e, por conseguinte, da saúde do paciente. Ademais, a falta de habilidades para lidar com dilemas éticos ou diferenças culturais, o desconhecimento da conjuntura política e administrativa que balizam o sistema de saúde e as noções de autocuidado são conhecimentos que influenciam diretamente na qualidade da interpretação.

Ainda que o Brasil conte com algumas leis de inclusão e leis de acesso linguístico, os debates acerca dos riscos envolvendo uso de intérpretes ad hoc em encontros médicos, bem como em outros contextos sociais, são inexpressivos ou quase inexistentes.

A experiência estadunidense, contexto de rápida profissionalização de 
QueIROz, M - Panorama da interpretação em contextos médicos no Brasil: Perspectivas

intérpretes da saúde na última década, chama a atenção para a necessidade de refletir sobre as leis linguísticas no Brasil e sobre os limites de aplicação de tais leis. Ademais, apontam para a necessidade de envolvimento das associações de tradutores e intérpretes e de reflexões teóricas na tomada de decisões no que diz respeito à profissionalização de um campo de interpretação da área da saúde, garantindo aos pacientes e provedores de serviços da saúde a oferta de intérpretes qualificados, bem como a remuneração adequada e a segurança dos intérpretes.

Os cursos de formação de intérpretes no Brasil estão substancialmente focados em contextos de conferências e no par de línguas português-inglês. Uma exceção parece ocorrer no curso de bacharelado de Letras-Libras da Universidade Federal de Santa Catarina, o qual está fazendo revisões em seu quadro de disciplinas, que agora inclui contextos intrassociais nas disciplinas de Estudos de Interpretação e laboratórios.

Futuramente, será necessário fazer uma reflexão sobre as proposições e os objetivos dessas ementas e uma avaliação dos seus resultados em relação ao desenvolvimento dos alunos nas habilidades necessárias para atuar em contextos específicos. Nesse sentido, compete às pesquisas realizadas na área dos Estudos da Tradução e Interpretação reformularem suas questões teórico-metodológicas a fim de atender a demandas de treinamento para intérpretes atuantes nos mais diferentes contextos ${ }^{9}$.

Baseado na proposta curricular Medint, este estudo conclui que 0 desenvolvimento de um campo profissional de intérpretes na área da saúde no Brasil depende da sensibilização pública por meio de parcerias institucionais e de diretrizes curriculares que possam ser utilizadas como base para diferentes cursos. Tais cursos devem em certa medida ter como objetivo o desenvolvimento dos conhecimentos, competências e habilidades necessários para a atuação em

\footnotetext{
${ }^{9}$ Para exemplos de tópicos de pesquisas na área, ver: WiLliams e CHESTERMAN 2002.
} 
QueIROz, M - Panorama da interpretação em contextos médicos no Brasil: Perspectivas

contextos médicos. Em curto prazo, pode-se pensar em currículos mais objetivos com carga horária curta, para que se possa estar minimamente preparado para atender às demandas atuais e emergenciais. A complexidade e a carga horária dos cursos devem se desenvolver com o tempo e com o envolvimento de profissionais das áreas ligadas à problemática. É certo que um programa de certificação no Brasil dependerá do desenvolvimento de cursos e do estabelecimento da atividade como campo profissional no país.

\section{Referências}

AngelelLl, C. Medical Interpreting and Cross-cultural Communication. UK: Cambridge, 2004 (a).

. Revisiting the interpreter's role: a study of conference, court, and medical interpreters in Canada, Mexico, and the United States. Amsterdam: John Benjamins, 2004 (b).

ANDERSON, R. B. Perspectives on the role of the interpreter. In: PöCHHACKER, F., SHLESINGER, M. Healthcare Interpreting: Discourse and Interaction. Philadelphya: J ohn Benjamins, 2007.

AverY, M. The Role of the Health Care Interpreter: An Evolving Dialogue. The National Council on Interpreting in Health Care: Working Paper Series, April 2001. Disponível em: http:// www. a2hc.org/articles/ The\%20role of health care interpreter. pdf. Acesso em: 25 set. de 2010.

BANCROFT, M. The Interpreter's World Tour: An Environmental Scan of Standards of Practice for Interpreters. In: NCIHC (Ed.). The California Endowment, 2005.

BAVLAY, A. et al. Ad hoc Interpreting in health care. In: Project: BiCom - 
QueIROz, M - Panorama da interpretação em contextos médicos no Brasil: Perspectivas

promoting bilingual and intercultural competencies in public health. Socrates Grundtvig 2: Learning Partnerships. Ancona, Hamburg, London, Utrecht, 2007.

BISCHOFF, A. Caring for migrant and minority patients. In: Forum for Migration and Population Studies, Neuchâtel the Institute of Nursing Science European hospitals: A review of effective interventions. Swiss: University of Basel, 2003.

BISCHOFF, A.; HUdELSON, P. Access to Healthcare Interpreter Services: Where Are We and Where Do We Need to Go? International Journal of Environmental Research and Public Health 2010. Disponível em: www.mdpi.com/journal/ijerph Acesso em: 15 jan. 2011.

BOWEN, M. Community Interpreting In: AICC. Legal and court Interpreting. 2000, Disponível em: http:// aiic.net/ViewPage.cfm/ page234.htm\#P5_365. Acesso em: 11 jun. 2010.

BRASIL. Lei $n^{\circ}$ 10.436, de 24 de abril de 2002. Dispõe sobre a Língua Brasileira de Sinais - Libras e dá outras providências. Disponível em: http:// www. planalto.gov. br/ CCIVIL/ LEIS/ 2002/ L10436.htm>. Acesso em: 08 mar. 2010.

CCHI. Job Task Analysis and Results. 2010. Disponível em: http:// www. healthcareinterpretercertification. org/ aboutus/ commissioners/ 106. html. Acesso em 14 ago. 2010.

De Pedro RIcoY, R. Training Public Service Interpreters in the UK: A fine balancing act. In: The Journal of Specialised Translation. n. 14, 100:120 July 2010. Disponível em: http:// www.jostrans.org/issue14/art_depedro.php. Acesso em: 10 dez. 2010.

ERTL, A., Pöllabauer, S. Training (Medical) Interpreters - the Key to Good Practice. MedInt: A Joint European Training Perspective. JosTrans, n. 14 Department of Translation Studies, University of Graz. 2010. Disponível em: http:// www.jostrans.org/ issue14/ art_ertl. php. Acesso em 02 de março de 2011.

FloRES, G. et al. Errors in Medical Interpretation and Their Potential Clinical Consequences Pediatric Encounters Pediatrics v. 111 n. 1, p. 6-14, jan. 2003. Disponível em: http:// pediatrics. aappublications.org/cgi/content/full/ 111/ 1/ 6. Acesso em: 10 jan. 2010. 
QueIROz, M - Panorama da interpretação em contextos médicos no Brasil: Perspectivas

FLORES, G. Cases From AHRQ WebM\&M: Language Barriers Are More Than an Inconvenience. Patient Errors Range From simple Miscommunication to LifeThreatening. MedScape Education, 2006. Disponível em: http:// www. medscape.com/ viewprogram/ 5533_pnt. Acesso em: 20 jan. 2010.

Giovanella, L. et al. Saúde nas fronteiras: acesso e demandas de estrangeiros e brasileiros não residentes ao SUS nas cidades de fronteira com países do MERCOSUL na perspectiva dos secretários municipais de saúde. Caderno Saúde Pública. Rio de J aneiro, v. 23, n. 2, p. 251- 266, 2007.

Gomes, A. M. de A.; Caprara, A.; Landim, L. O. P. and Vasconcelos, M. G. F. Relação médico-paciente: entre o desejável e o possível na atenção primária à saúde. Physis [online]. 2012, vol.22, n.3, pp. 1101-1119.

J OINT COMmISsION. Providing Culturally and Linguistically Competent Health Care. USA: 2010.

. Patient-Centered Communication Standards \& EPs - Hospital

Accreditation Program. Issue 1. USA: 2011. Disponível em: http:/ / www.jointcommission.org/ assets/ 1/ 18/ R3\%20Report\%20lssue\%201\%20201 11. PDF. Acesso em: 20 mar. 2011.

KAUgeRT, J .; O' NEIL, J. Biomedical rituals and informed consent: native Canadians and the negotiation of clinical trust. In: WEISZ, G. (ed.) Social science perspectives on medical ethics. Kluwer Academic Publishers: Netherlands, 1990.

KELLY, N. The marketing for medical interpreting certification. In: the Global Watchtower. Out. 2010 Disponível em: www.globalwatchtower.com/2009/10/13/ certification-market/ Acesso em: 13 abr. 2010.

- Telephone Interpreting: a comprehensive guide to the profession. USA: Trafford, 2008.

KU, L.; FlORES, G. Pay Now Or Pay Later: Providing Interpreter Services In Health Care. Health Affairs, v. 24, n. 2. p. 435-444, 2006.

LAMBERT, J. Globalization. Disponível em: http:/ / groups. google.com. br/ group/ traduction-dynamique/ files?hl=pt- 
QueIROz, M - Panorama da interpretação em contextos médicos no Brasil: Perspectivas

BR. Acesso em: 10 nov. 2009.

LEANZA, Y. Roles of community interpreters in pediatrics, as seen by interpreters, physicians, and researchers. In: Healthcare Interpreting: Discourse and Interactlion, USA: J onh Benjamins, 2008.

MelO, E. Apenas cinco intérpretes da língua indígena auxiliam saúde pública em RR. Jornal do Meio Ambiente. 9/2/2012. Disponível em: http:// www.jornalmeioambiente.com/ materia/ 2142/ apenas-cinco-interpretesda-lingua-indigena-auxiliam-saude-publica-em-rr. Acesso em: 26 fev. 2011.

METZGER, M. Sign language interpreting: deconstructing the myth of neutrality. Gallaudet University Press: Washington, DC, 1999.

MitchelL, R. Et al. How Many People Use ASL in the United States? Why Estimates Need Updating. Sign Language Studies, Vol. 6, No. 3, 2006.

MOORE, J.; SWABEY L. Medical Interpreting: A Review of the Literature. CATIE, College of St. Catherine/NCIEC, 2007. Disponível em: http:// www. medicalinterpreting.org/ PDF/ DRAFTLitReview. pdf. Acesso em: 14 fev. 2011.

NisKA, H. Community interpreter training: Past, present, future. In: GARZONE, G.; VIEZZI, M. (eds. ), Interpreting in the 21st Century. Amsterdam/ Philadelphia: J ohn Benjamins, p. 133-144, 2002.

- Training interpreters: programmes, curricula and practices. In: TENNENT, M. (ed.): Training for the new millennium. John Benjamins: Amsterdam, p. 35-64, 2005.

NoRDIN, J. Manual de boas práticas do intérprete judicial. Primeiro Simpósio Brasileiro de Interpretação. São Paulo: USP, 2013. (Comunicação oral).

ONG, L.M.; DE HAES, J.C.; HoOS, A.M.; LAMMES, F.B. Doctor-patients communication: a review of the literature. Soc Sci Med., n. 40, p. 903-918, 1995.

PÖCHHACKER, F. Introducing Interpreting Studies. London and New York: Routlegde, 2004.

. Conexões Fundamentais: Afinidade e Convergência

TradTerm, São Paulo, v. 23, Setembro/2014, p. 193-223

www. usp. br/tradterm

http:// www. revistas. usp.br/tradterm/index 
QueIROz, M - Panorama da interpretação em contextos médicos no Brasil: Perspectivas

nos Estudos da Interpretação. Tradução: Mylene Queiroz. Scientia Traductionis, n. 7, UFSC, Florianópolis, 2010.

PöChHACKER, F.; KADRIC, M. The Hospital Cleaner as Healthcare Interpreter. The Translator, v. 5, n. 2, p. 161-178, 1999.

PÖCHHACKER, F.; SHLESINGER, M. Healthcare Interpreting: Discourse and Interaction. Amsterdam: J ohn Benjamins, 2007.

POKORN, N. K. Medint: Development of a Curriculum for Medical Interpreters. Summary Reports: Work package 6, 2008. Disponível em: http:// www.unigraz.at/wp6_curriculum_final.pdf. Acesso em: 01 dez. 2010.

PSI SeRviCES LLC. Development and Validation of Oral and Written Examinations for Medical Interpreter Certification. Technical Report, 2010. Disponível em: http:// www. diversityrxconference. org. Acesso em: 10 jun. 2010.

QueIROZ, M. Interpretação Médica no Brasil. 2011. 136 f. Dissertação (Mestrado em Estudos da Tradução) - Pós Graduação em Estudos da Tradução, Universidade Federal de Santa Catarina, Florianópolis. 2011.

ROBERTS, L. W. et al. When providers and patients come from different backgrounds: perceived value of additional training on ethical care practices. Transcult Psychiatry. 2008 Disponível em: http:// www. ncbi.nlm. nih. gov/ pubmed/ 19091725. Acesso em: 03 mar. 2011.

. Community Interpreting: A Profession in Search of Its Identity. In: HUNG, E. (ed.) Teaching Translation and Interpreting 4 Building Bridges. Amsterdam/ Philadelphia: J ohn Benjamins, p.157-175, 2002.

RUDVIN, M. Negotiating linguistic and cultural identities in interpreter-mediated communication for public health services. In: PYM, A. et al. Social Aspects of Translation and Interpreting. Philadelphia: J ohn Benjamins, 2003.

SCHILLINGER, D.; CHEN, A.H. Literacy and language: disentangling measures of access, utilization, and quality. Journal of General Internal Medicine, n. 19, v. 3, p. 88-90, 2004.

StewART, M.A. Effective physician-patient communication and health outcomes: a 
review. Can Med Assoc J., n. 152, p. 1423-1433, 1995.

URPI, M. La interpretatación social. Estat de La questió. El cãs Del col lectiu xinès: especificitats reptes. Dissertação de mestrado apresentado no Programa Oficial de Postgrau de Tradució i interpretació i els seus contextos socioculrurals. Univeritat attonoma de Barcelona. Barcelona, 2009.

WHALEY, B. Explaining illness: research, theory, and strategies. Mahwah, NJ : Lawrence Erlbaum Associates, 2000.

WADENSJ Ö, C. Interpreting as Interaction: On Dialogue Interpreting in Immigration Hearings and Medical Encounters. Linköping University: Linköping, 1992.

Williams, J.; Chesterman, A. The Map: A Beginner's Guide to Doing Research in Translation Studies. UK: St. J erome, 2002.

WENINGER, M.; QUEIROZ, M. Interpretação na área da saúde em Libras-Português: abordagem teórica, retrato da prática e tarefas para o futuro. In: QUADROS, R.; WENINGUeR, M. (org.) Estudos de Línguas de Sinais 3. Florianópolis: Insular, 2014. 